\section{Ein Armutszeugnis für die deutsche Tourismuswirtschaft}

Die Unterzeichnung einer über 13 Jahre alten, nicht bindenden

Absichtserklärung ist eigentlich kaum eine Meldung wert. Dass

der Deutsche Reiseverband (DRV) dies als großes Ereignis

feiert, ist eher ein Armutszeugnis für den Stellenwert der

Nachhaltigkeit in der deutschen Tourismuswirtschaft.

Von Wolfgang Strasdas

$F^{2}$ ünf Jahre nach der Rio-Konferenz begann die Welttourismusorganisation (UNWTO) mit der Entwicklung des Globalen Ethik-Kodex für den Tourismus. Heraus kam weitere zwei Jahre später eine Erklärung, die allgemeine Grundsätze zur sozialen und wirtschaftlichen Nachhaltigkeit des internationalen Tourismus enthält, daneben aber auch ein „Recht auf Tourismus“ fordert und diesen gar als „Weg zur individuellen und kollektiven Erfüllung“ bezeichnet.

\section{Globaler Ethik-Kodex der Welttourismusorganisation}

Man wird den Eindruck nicht los, dass es hierbei vor allem darum geht, die wirtschaftlichen Interessen einer Branche zu schützen, die sich durch ein „rasches und anhaltendes Wachstum“ auszeichnet, hinsichtlich ihrer ökologischen und sozialen Wirkungen aber in die Kritik geraten ist.

Dies wird am deutlichsten im Umgang der UNWTO und der internationalen Tourismuswirtschaft mit dem von ihr mitverursachten Klimawandel. Versuche, die Branche zu einer Reduktion ihrer Treibhausgasemissionen zu verpflichten, werden regelmäßig mit dem Argument abgewehrt, der Tourismus trage zur Armutsminderung in Entwicklungsländern bei und dürfe daher nicht beschränkt werden. Es ist sicher kein Zufall, dass man das Wort Klimawandel im Ethik-Kodex vergeblich sucht.

\section{Das Potenzial des Reisens}

Als Professor für Nachhaltiges Tourismusmanagement stelle ich das Potenzial des Reisens und der Tourismuswirtschaft für eine nachhaltige Entwicklung nicht grundsätzlich infrage - ganz im Gegenteil. Auch bestreite ich nicht, dass globale Absichtserklärungen trotz der nicht immer vermeidlichen Kompromisse eine gewisse Orientierungsfunktion haben können. Der Globale Ethik-Kodex der UNWTO jedoch war schon 1999 nichts Bahnbrechendes mehr und ist inzwischen von der Zeit vollends überholt worden. Der Kodex müsste eigentlich dringend überarbeitet und konkretisiert werden.

Das bringt mich zu der Frage, wieso der DRV und die beteiligten Unternehmen in 2012 ein solches Dokument unterzeichnen. Wenn überhaupt, warum dann nicht schon viel früher? Der DRV hat den Umweltschutz schon in den frühen 1990er Jahren zu einem Thema gemacht - zu einer Zeit als das Umweltbewusstsein der deutschen Bevölkerung besonders hoch war und man erwarten konnte, dass sich eine entsprechende Positionierung auszahlen würde.

Seitdem ist wenig passiert, eher das Gegenteil war der Fall. In den Jahren nach der Veröffentlichung des 4. Sachstandsberichtes des Weltklimarates in 2007 setzte sich die deutsche Tourismuswirtschaft, allen voran die Fluggesellschaften und die großen Reiseveranstalter, vehement gegen

\title{
ounkt
}

eine Reglementierung des Flugverkehrs zum Schutz des globalen Klimas ein.

Und nun also die öffentlichkeitswirksame, aber folgenlose Unterzeichnung eines veralteten Kodex, dessen Inhalte längst selbstverständlich sein sollten. Es zeugt, höflich gesagt, von wenig Veränderungsbereitschaft - und wohl auch von einer gewissen Ratlosigkeit, wie es in puncto Nachhaltigkeit weitergehen soll.

\section{Nachhaltiger Tourismus ist möglich}

Dabei gibt es deutlich anspruchsvollere und auch sehr konkrete Möglichkeiten, das eigene Wirtschaften nachhaltiger zu gestalten, wie etwa die Einführung von CSR-Managementsystemen, die auch extern zertifizierbar sind (zum Beispiel TourCert), die Anwendung von Fair Trade-Prinzipien im Tourismus, formalisierte Emissions-Audits als Grundlage für ein konsequentes Carbon Management mit dem Ziel der Emissionsminderung, Gu idelines für Biodiversitäts-Checks von Unternehmen und viele weitere.

Einige der unterzeichneten Unternehmen, wie zum Beispiel Studiosus oder Gebeco, haben sich schon auf den Weg gemacht; sie sind aber noch Ausnahmen. Ein wirkliches Ausrufezeichen könnte der DRV setzen, wenn er diesen ersten Pionieren folgen und als Spitzenverband wirklich anspruchsvolle Branchenstandards setzen würde.

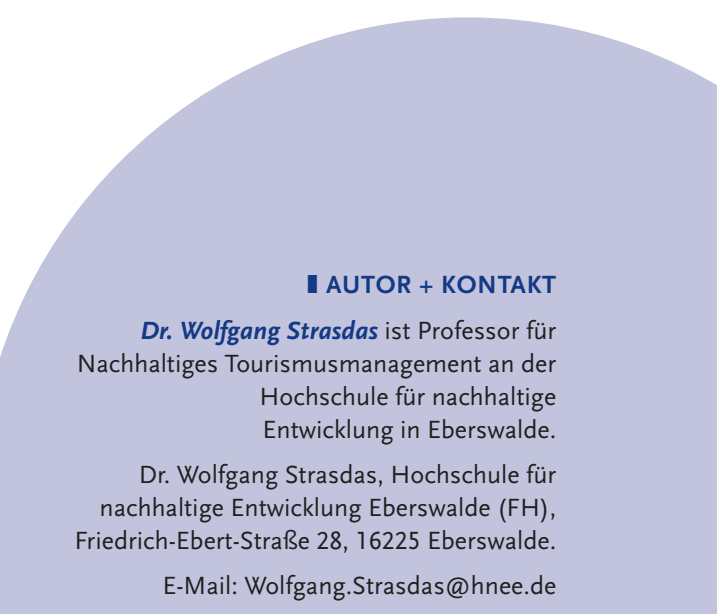


Copyright (C) 2013, IÖW und oekom Verlag. Die Nutzung des Artikels ist Abonnenten von Ökologisches Wirtschaften vorbehalten. Nachdruck und Vervielfältigung des Artikels einschließlich Speicherung und Nutzung auf optischen und elektronischen Datenträgern nur mit Zustimmung der Redaktion von Ökologisches Wirtschaften (http://www.oekologischeswirtschaften.de). 